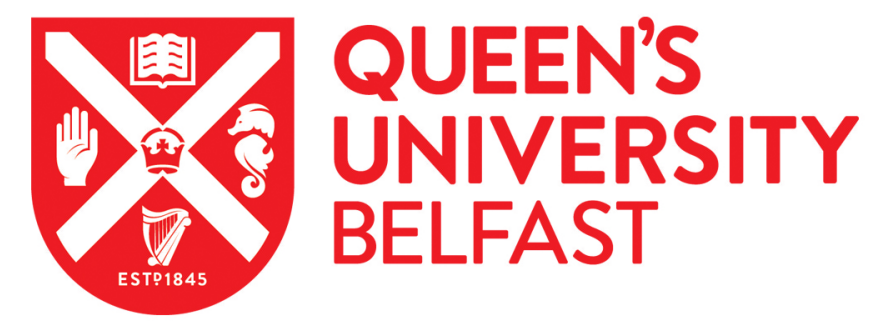

\title{
Using EPR Spectroscopy as a Unique Probe of Molecular-Scale Reorganization and Solvation in Self-Assembled Gel-Phase Materials
}

Caragheorgheopol, A., Edwards, W., Hardy, J. G., Smith, D. K., \& Chechik, V. (2014). Using EPR Spectroscopy as a Unique Probe of Molecular-Scale Reorganization and Solvation in Self-Assembled Gel-Phase Materials. Langmuir, 30(30), 9210-9218. https://doi.org/10.1021/la501641q

\section{Published in:}

Langmuir

\section{Document Version:}

Peer reviewed version

Queen's University Belfast - Research Portal:

Link to publication record in Queen's University Belfast Research Portal

\section{Publisher rights}

This document is the Accepted Manuscript version of a Published Work that appeared in final form in Langmuir, copyright $\odot$ American Chemical Society after peer review and technical editing by the publisher. To access the final edited and published work see http://pubs.acs.org/doi/abs/10.1021/la501641q.

\section{General rights}

Copyright for the publications made accessible via the Queen's University Belfast Research Portal is retained by the author(s) and / or other copyright owners and it is a condition of accessing these publications that users recognise and abide by the legal requirements associated with these rights.

Take down policy

The Research Portal is Queen's institutional repository that provides access to Queen's research output. Every effort has been made to ensure that content in the Research Portal does not infringe any person's rights, or applicable UK laws. If you discover content in the Research Portal that you believe breaches copyright or violates any law, please contact openaccess@qub.ac.uk. 


\section{Using EPR Spectroscopy as a Unique Probe of Molecular-Scale Reorganization and Solvation in Self-Assembled Gel-Phase Materials}

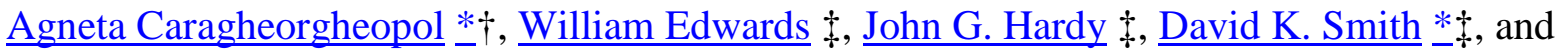
Victor Chechik $*+$

${ }^{\dagger}$ Ilie Murgulescu Institute of Physical Chemistry, Romanian Academy, 202 Spl. Independentei, Bucharest 060021, Romania

‡ Department of Chemistry, University of York, Heslington, York YO10 5DD, UK

Langmuir, 2014, 30 (30), pp 9210-9218

DOI: $10.1021 / \mathrm{la501641q}$

Publication Date (Web): July 13, 2014

Copyright (C) 2014 American Chemical Society

*E-mail agi_gartner07@yahoo.com (A.C.)., *E-mail david.smith@york.ac.uk (D.K.S.)., *Email victor.chechik@york.ac.uk (V.C.).

\section{Abstract}
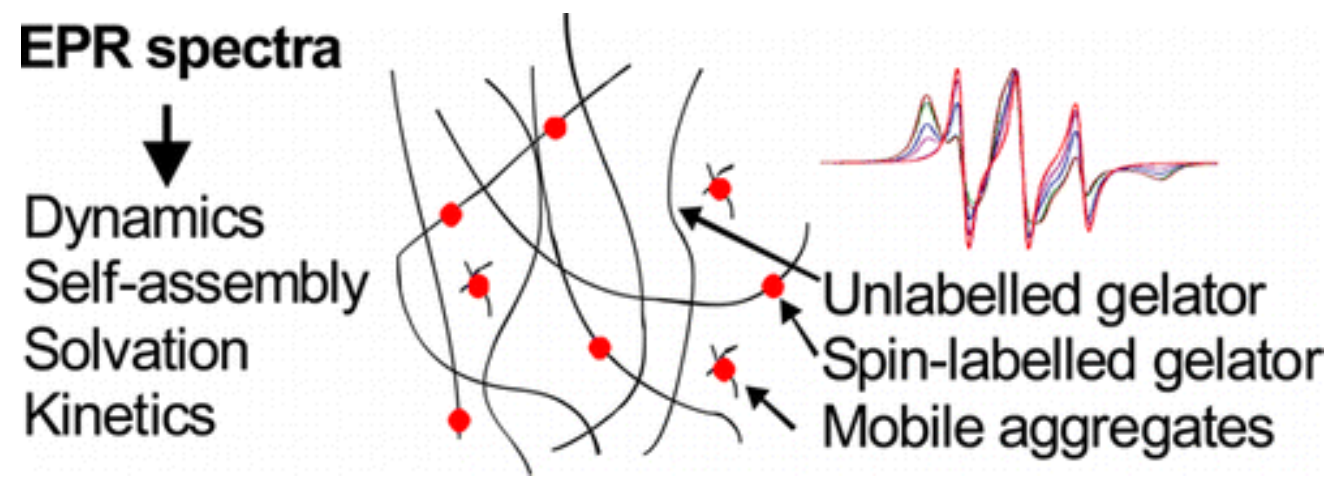

We describe the synthesis of spin-labeled bis-ureas which coassemble with bis-urea gelators and report on self-assembly as detected using electron paramagnetic resonance spectroscopy (EPR). Specifically, EPR detects the gel-sol transition and allows us to quantify how much spin-label is immobilized within the gel fibers and how much is present in mobile solvent pools - as controlled by temperature, gelator structure, and thermal history. EPR is also able to report on the initial self-assembly processes below the gelation threshold which are not macroscopically visible and appears to be more sensitive than NMR to intermediate-sized nongelating oligomeric species. By studying dilute solutions of gelator molecules and using either single or double spin-labels, EPR allows quantification of the initial steps of the hierarchical self-assembly process in terms of cooperativity and association constant. Finally, EPR enables us to estimate the degree of gel-fiber solvation by probing the distances between spin-labels. Comparison of experimental data against the predicted distances assuming the nanofibers are only composed of gelator molecules indicates a significant difference, which can be assigned to the presence of a quantifiable number of explicit solvent molecules. In summary, EPR provides unique data and yields powerful insight into how molecular-scale mobility and solvation impact on assembly of supramolecular gels. 


\section{Introduction}

Gel-phase materials have attracted much attention due to their hierarchical assembly, in which molecular-scale features direct self-assembly into nanoscale fibrils, which bundle further into fibers, and ultimately form an enmeshed three-dimensional network with macroscopic properties reflecting all levels of the assembly process. $(1,2)$ These colloidal gels are of particular interest due to the unique way in which they combine an immobile "solid-like" nanoscale network with a mobile "liquid-like" solvent phase. These soft materials have been suggested for applications ranging from tissue engineering matrices to interfaces between biological and electronic materials.(3-5)

Clearly, understanding the unique features of gels is of great significance, as a better understanding of all steps in the hierarchical assembly pathway will enable more effective gelator design and greater prediction of the way in which molecular-scale changes can impact on macroscopic properties. $(6,7)$ Various characterization techniques have been demonstrated to be particularly useful in dissecting different aspects of gel behavior. $(8,9)$ For example, spectroscopic techniques report effectively on molecular-scale assembly, microscopy and Xray scattering methods provide insight into the nanoscale regime, and rheological and calorimetric methods characterize the macroscopic interactions of the supramolecular polymer assemblies. $(8,9)$ NMR spectroscopy is often used to investigate the mobility of molecular-scale building blocks within gels-indeed, this technique enables quantification of how much material is present within the liquid-like phase and its mobility — data that have been used to address chemo- and enantioselectivities in multicomponent gels.(10-12) In recent years, electron paramagnetic resonance (EPR) spectroscopy and spin-probe/spinlabel methods have become an important tool in the study of nanoscale materials.(13) EPR provides unique insight into the local environment around the spin probes, interactions with other electron (and nuclear) spins on a nanometer scale, and mobility on the nanosecond time scale and, as such, can provide detailed information about the short- and long-range nanostructuring of molecular-scale building blocks within complex assembled systems. Although most spectacular examples come from structural biology,(14) where EPR has been successfully used to explore protein and DNA structure, dynamics, and interactions, similar approaches were exploited to investigate other supramolecular systems,(15) e.g., colloidal structures,(16) host-guest complexes,(17) coordination cages,(18) polymer aggregates,(19) mesoporous materials,(20) and nanoparticles.(21) We thus reasoned that spin-labeling would be a powerful approach to investigate gel-phase materials and, perhaps surprisingly, found that this method has only very rarely been used to characterize gels.(7) In particular, supramolecular gels formed by self-assembly of small molecule gelators are highly amenable to site-specific spin-labeling, and yet there are very few examples of EPR studies of these materials. It has been noted that EPR can report on the gel-sol transition,(22) including in complex liquid-crystalline gels,(23) as well as detecting smaller aggregates.(24) There has also been some interest in incorporating stable organic radicals into gelators in order to generate magneto-materials. $(25,26)$ However, to fully explore the scope of EPR and avoid unwanted radical-radical interactions, the spin-labeled gelators must be incorporated into an unlabeled gel, and this remains an almost untouched area. EPR spectroscopy does not feature in recent reviews on characterization of supramolecular gels. $(8,9)$

We decided to use spin-labels in order to probe organization within supramolecular gels. Spin-labels always have the potential to disturb the system being measured, and for supramolecular gels based on noncovalent interactions this can be significant. We have previously observed a number of examples where a spin-labeled gelator failed to get incorporated into the gel network. As such, it is essential to ensure strong interactions 
between the spin-labeled gelator and the gel fibers, so that the label can effectively report on the nanostructured environment in which it finds itself. We therefore designed a number of spin-labeled molecules based on the bis-urea motif, which is widely used in self-assembled organogels owing to the ability of the urea functional groups to form strongly hydrogenbonded fibers (Figure 1).(27, 28) Importantly, this paper demonstrates EPR is a powerful technique to probe mobility in gels, allowing us to study self-assembly below the gelation threshold and the explicit solvation of gel fibers.<smiles>[R]NC(=O)NCCCCC(NC(=O)N[R])C(=O)OC</smiles>
DLD: $\mathrm{R}=\mathrm{C}_{12} \mathrm{H}_{23} ;$ OLO: $\mathrm{R}=\mathrm{C}_{8} \mathrm{H}_{17}$<smiles>[R]NC(=O)NCCCCC(NC(=O)NC1CC(C)(C)N([O])C(C)(C)C1)C(=O)NC(CCCCNC(=O)NC1CC(C)(C)N(OC(C)C)C(C)(C)C1)C(=O)OC</smiles>

DLT: $\mathrm{R}=\mathrm{C}_{12} \mathrm{H}_{23} ;$ OLT: $\mathrm{R}=\mathrm{C}_{8} \mathrm{H}_{17}$<smiles>COC(=O)C(CCCCNC(=O)NC1CC(C)(C)N(O[O])C(C)(C)C1)NC(=O)NC1CC(C)(C)N([O])C(C)(C)C1</smiles>

TLT

Figure 1. Structures of gelators/compounds with zero, one, and two spin-labels, as used in this study.

\section{Results and Discussion}


Preparation of Spin-Labeled Gels

We synthesized a small family of gelators from commercially available lysine methyl ester di-isocyanate (LDI). These molecules either contained zero, one, or two spin-labels. The gelators were synthesized using a method reported previously in which the appropriate amine nucleophile (octylamine, dodecylamine, or amino-TEMPO) was reacted with LDI, giving OLO, DLD, and TLT, respectively.(29, 30) Products OLT and DLT with one amino-TEMPO and one alkyl chain (octylamine or dodecylamine, respectively) were synthesized by the reaction of LDI with 1 equiv of amino-TEMPO followed by reaction with excess alkylamine. These compounds were used as a mixture of two positional isomers which gave a single spot on the TLC and could not be separated by flash chromatography. Compound naming reflects the central lysine (L) group flanked with (two of) a dodecyl chain (D), an octyl chain (O), or a TEMPO spin-label (T).

We used these compounds to form spin-labeled gels as follows. An unlabeled gelator (e.g., DLD) containing a small amount of a labeled gelator (e.g., DLT) was heated in toluene at 100 ${ }^{\circ} \mathrm{C}$ followed by cooling to room temperature to allow the gels to fully form and equilibrate overnight. Gels were typically made at $5 \% \mathrm{w} / \mathrm{v}$ (ca. $88 \mathrm{mM}$ for a gel based on DLD). The final concentration of the spin-labeled compound was $0.1 \mathrm{mM}$ - as such, the unlabeled gelator was by far the dominant species present in the gel. The gel-sol transition temperature ( $\left.T_{\text {gel }}\right)$ of the $5 \%$ DLD/DLT gel made in toluene in this way was determined by the tube inversion method as $80^{\circ} \mathrm{C}$ (all gel studies, including visual thermal investigations, were carried out with $0.1 \mathrm{~mL}$ gel samples in $5 \mathrm{~mm}$ NMR tubes). We also measured the $T_{\text {gel }}$ value for the $2 \%$ DLD/DLT gel which was, as expected, lower at $72{ }^{\circ} \mathrm{C}$. The $5 \%$ OLO/OLT gel had a higher thermal stability of $90^{\circ} \mathrm{C}$.

Preliminary EPR Study: Solid-like and Liquid-like Components Figure 2 shows the EPR spectra of the 5\% DLD/DLT gel, in which the spin-labeled DLT probe has a single TEMPO unit, at different temperatures. The spectra suggest the coexistence of a very slowly moving, almost solid-like, species with a rapidly tumbling one (see below for further details of deconvolution). When the concentration of the DLT in the $5 \%$ DLD/DLT gel was varied over a wide range $\left(2.5 \times 10^{-5}-10^{-3} \mathrm{M}\right)$, the EPR spectra were identical, with the same proportion of mobile and immobile species. This is consistent with the equilibrium distribution of the label between the two different environments. At $298 \mathrm{~K}$, the slowly tumbling species appears to be dominant, while on increasing the temperature, the relative contribution of this solid-like component decreases, whereas the contribution of the rapidly tumbling mobile component increases. Above ca. $353 \mathrm{~K}$, the spectrum only shows the rapidly tumbling species. The observation of very significant changes in the EPR spectra in the same temperature range as the macroscopic gel-sol transition suggests that the labeled gelator is indeed reporting on the microscopic changes in the overall gel which take place during the gel-sol transition. We therefore conclude that the DLT label is incorporated within the DLD gel network as a consequence of bis-urea hydrogen bond interactions and is a suitable probe for exploring the molecular and supramolecular structure of the DLD selfassembled gel. 


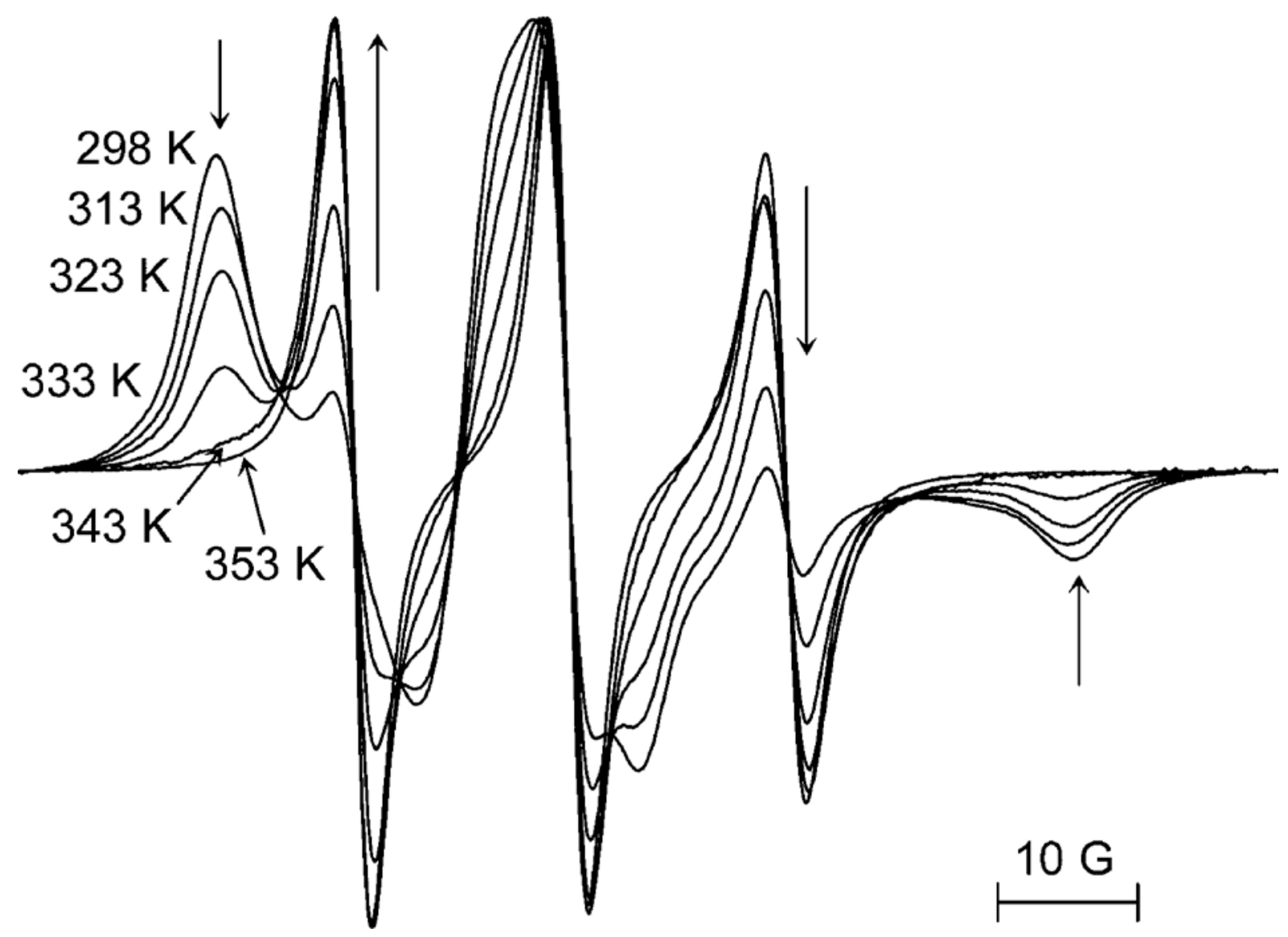

Figure 2. EPR spectra of a 5\% DLD gel with $0.1 \mathrm{mM}$ DLT label at different temperatures. The arrows indicate the changes in the line shape with increased temperature.

The separation of two components in the EPR spectra as solid-like and liquid-like components (Figure S1) was then studied in more detail. Figure $\underline{3}$ compares the EPR spectra of the solid-like component of the solvated gel at $120 \mathrm{~K}$ and at room temperature with those of TEMPO and the xerogel obtained by drying the DLD/DLT gel under vacuum, respectively. We believe this solid-like component represents the spin-labeled gelator incorporated into the gel fibers. The separation of the outermost peaks in the EPR spectra of frozen solutions (recorded at $120 \mathrm{~K}$ ) equals $2 A_{\mathrm{zz}}$. The $A_{\mathrm{zz}}$ value of nitroxides (such as TEMPO) depends on solvent polarity.(31) The almost identical spectra of the gel $\left(2 A_{\mathrm{zz}}=68.2\right.$ $\mathrm{G})$ and TEMPO $\left(2 A_{z z}=68.7 \mathrm{G}\right)$ at $120 \mathrm{~K}$ suggest that the label in the gel experiences a nonpolar environment similar to toluene. At room temperature, however, the separation of the outermost peaks in the EPR spectra of the solid-like gel component is also affected by the molecular tumbling. As the peak separation slightly decreases (60.9 G) compared to that at $120 \mathrm{~K}$ (Figure $\underline{3}$ ), we conclude that the spin-label incorporated in the gel fibers is not completely immobilized but has some residual motion on the EPR time scale at room temperature. We were unable to obtain a satisfactory simulation of this spectrum using a simple anisotropic Brownian diffusion model.(32) This suggests the spin-label is not completely free and can only access highly restricted conformational space by librating in the gel fibers. In any case, the presence of residual mobility of the molecules in the gel fibers (not observed in frozen solutions or solid matrices) is significant. We also note that the dried xerogel shows almost (but not quite) the same residual mobility as the solvated gel (62.5 G, Figure $\underline{3}$ ). This experiment clearly suggests that the "solid-like" component in these gels is 
not completely immobile/crystalline in nature-EPR therefore provides a powerful technique for providing insight into this unique dynamic aspect of gel-type materials.

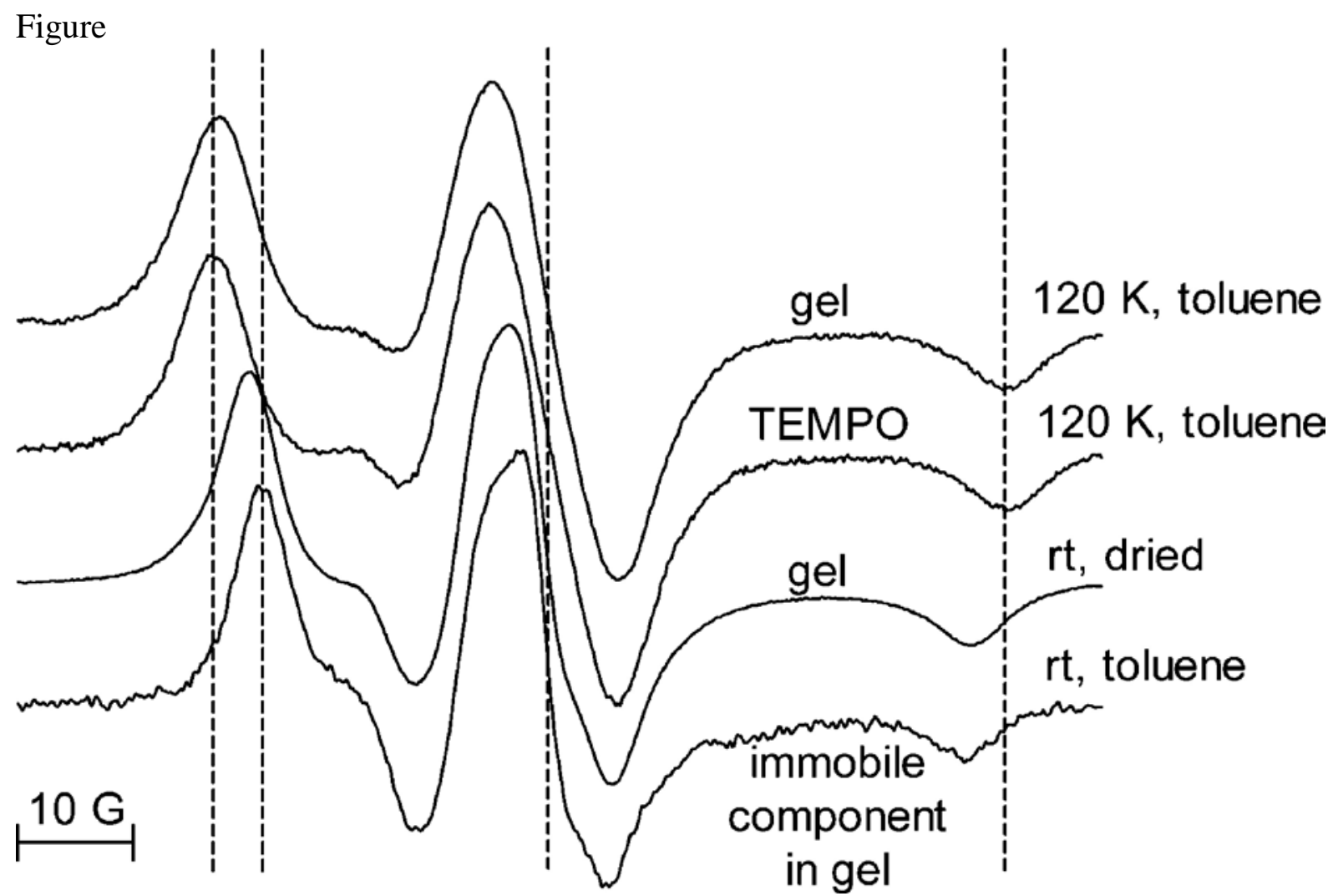

3. Comparison of EPR spectra of a 5\% DLD/DLT gel and $0.1 \mathrm{mM}$ TEMPO solution in toluene at different temperatures.

Upon heating, below the gel transition temperature, the relative contribution of the solid-like component decreases, but the separation of the outermost peaks remains almost unchanged (Figure 2). This suggests that heating the gel leads to some desorption of gelator molecules from the fibers (vide infra), but the mobility of the molecules which remain incorporated into the gel network does not significantly increase.

We also deconvoluted the EPR spectra of the mobile component of the 5\% DLD/DLT gel (Figure 4). When recorded at $323 \mathrm{~K}$, the spectra varied somewhat depending on the thermal history of the gel (Figure 4) - for example, whether the samples were being heated or cooled (for more details see discussion on gel reversibility below). All spectra showed somewhat restricted motion of the "mobile" spin-label, but the precise extent of this varied. The restricted tumbling implies that this component is not a truly "free" label in the solvent pool, as this would rapidly tumble. To illustrate this, we recorded an EPR spectrum of cholestane doxyl in the DLD gel. Cholestane doxyl is a large, rigid spin probe and hence would be expected to show more restricted tumbling in solution than the smaller DLT molecule. However, cholestane doxyl lacks any functional groups capable of strong hydrogen bonding and was thus expected to stay in the solvent pools rather than be incorporated into the gel fibers. The EPR spectrum indeed showed that cholestane doxyl undergoes almost unrestricted tumbling on the EPR time scale in both toluene and the gel (rotational correlation time at 323 $\mathrm{K}, \tau_{\mathrm{c}}=0.48 \times 10^{-10} \mathrm{~s}$ ). If the DLT spin-label was truly mobile in the gel, it should therefore show the same or even faster tumbling behavior. It does not, and as such, we conclude that 
the mobile DLT spin probes present in the supramolecular gel are actually associated with larger structures, but which still possess some significant mobility. We suggest that these species are gelator oligomers of different sizes that are not incorporated in macroscopic assemblies (see below). The only exception is EPR spectra of gels at room temperature which show a very small mobile component with almost unrestricted tumbling, e.g., free DLT molecules. We thus conclude that at temperatures much below the gelation point the gel fibers coexist with very small amounts of free gelator. With increasing temperature, gelator molecules progressively desorb from the fibers, forming oligomers of different sizes.

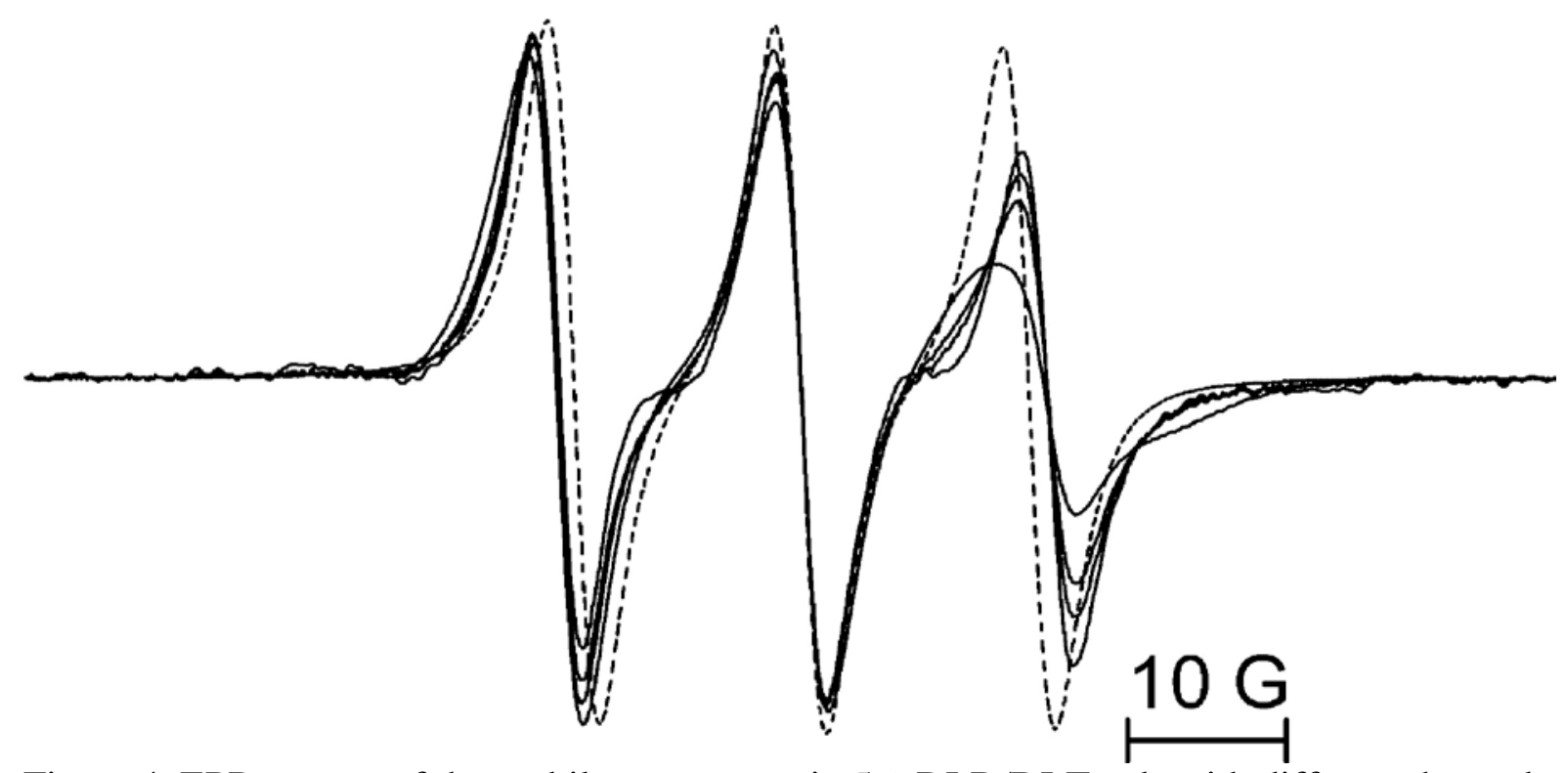

Figure 4. EPR spectra of the mobile component in 5\% DLD/DLT gels with different thermal histories recorded at $323 \mathrm{~K}$ (solid lines). EPR spectrum of fully mobile cholestane doxyl in the $5 \%$ DLD gel at $323 \mathrm{~K}$ is shown as a dashed line.

To explore the sensitivity of gel composition to structural variation, we recorded the EPR spectra of a 5\% OLO/OLT gel at different temperatures (Figure S3). The spectra showed very similar behavior to that of 5\% DLD/DLT gels; however, the relative proportion of the mobile component in the 5\% OLO/OLT gels was higher (the contribution of the mobile component in the 5\% DLD/DLT and 5\% OLD/OLT gels at room temperature was 6 and 13\%, respectively). This suggests that increasing the length of the alkyl chains favors incorporation of the oligomers into the fibers.

In order to probe mobility within the gels further, we put a large excess of pure toluene on top of a sample of the 5\% OLO/OLT gel. Over a time period of $16 \mathrm{~h}$, the signal of the partially mobile component in the gel gradually decreased, and the toluene layer showed a spectrum typical of a completely free gelator, i.e., unrestricted tumbling on the EPR time scale. This implies that gelator oligomers can diffuse through the gel into the large volume of the bulk solvent where they break apart in the dilute conditions. The slow changes in the mobile component over time also suggest that the equilibrium distribution of the gelator between mobile and immobile components does not establish quickly in this system.

To summarize, our data suggest that the spin-labeled gelator molecules in supramolecular gels are associated not only within solid-like gel fibers but also within oligomers that are not incorporated in macroscopic assemblies. The ratio between the fibers and soluble oligomers strongly depends on (i) how far the temperature is from $T_{\text {gel }}$ (as temperature increases, so 
does the amount of soluble oligomer) and (ii) the structure of the gelator (OLO/OLT and DLD/DLT have different ratios of mobile/immobile components).

Reversibility of Gelation: Kinetics of Gel Assembly

One of the interesting features of gels is that they often convert reversibly into sols-with heating and cooling cycles giving rise to macroscopic gel-sol and sol-gel transitions.

However, it is known that there is frequently a kinetic barrier to the sol-gel transition, as can be seen from the hysteresis loop present in differential scanning calorimetry $(33,34)$ and the induction time for gelation observed in some NMR or CD experiments.(35, 36) We were therefore interested in the ability of EPR to report on the molecular-scale reversibility of gelation.

We showed above (Figure 2) that at temperatures approaching $T_{\text {gel }}$ supramolecular gels consist of a mixture of fibers and gelator aggregates in temperature-dependent proportions. We noticed that increasing the temperature of the gel leads to immediate changes in the EPR spectra. If the temperature was then kept constant, the spectra remained unchanged over time. However, we found that on cooling the gel to a lower temperature, the EPR spectrum did not immediately return to the original line shape. For example, when gels were heated to $373 \mathrm{~K}$ and then installed in the EPR cavity at $323 \mathrm{~K}$, significant changes in the EPR line shape were observed over 90 min (Figure $\underline{5}$ ). The changes in the EPR line shape over time must be due to the slow reorganization of the gel and mass transfer between the soluble aggregates and gel fibers (i.e., there is a kinetic barrier to gelation) — even though visually the gel properties did not change over time.

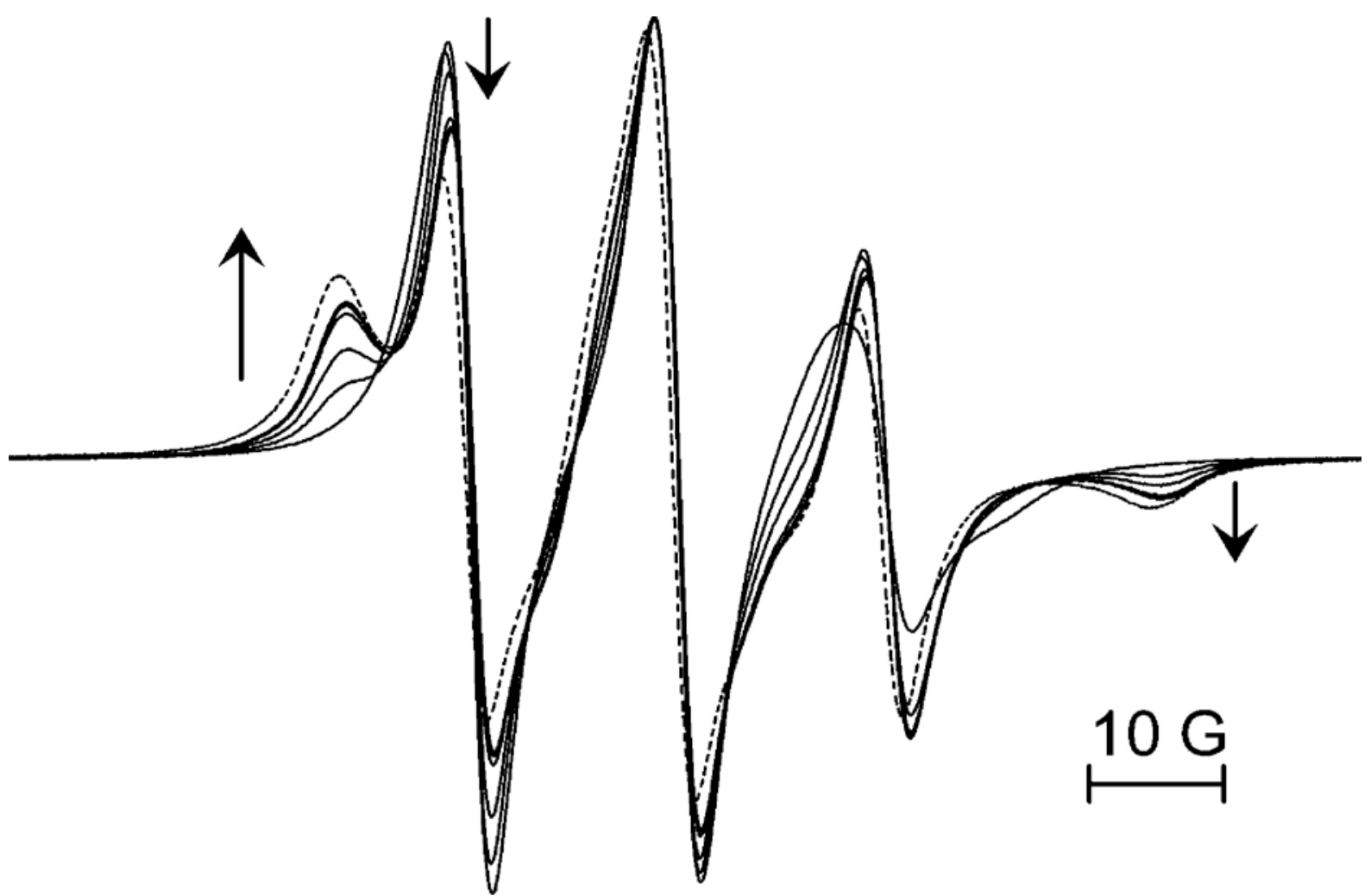

Figure 5. Changes in the EPR spectrum of a 5\% DLD/DLT gel cooled from 373 to $323 \mathrm{~K}$. The spectra were recorded at the following times after achieving the lower temperature: 19, $24,28,49,72$, and $85 \mathrm{~min}$. The arrows show the changes in the line shape over time. The dashed line shows the spectrum after equilibration overnight. 
These results clearly indicate that breaking fibers in a supramolecular gel is a fast process, with heating leading to rapid dissociation of gelator. However, the reverse process - selfassembly of the gelator molecules and oligomers into nanofibers on cooling-is a much slower process which can take hours. This can be rationalized considering the incorporation of a gelator aggregate into a gel fiber as a complex process that involves not only the formation of new hydrogen bonds but also potentially the breaking of hydrogen bonds in both the fiber and the oligomer and the structural reorganization of the molecules in the oligomer and, possibly, in the gel fiber itself, prior to attachment of the monomer/oligomer to the fiber. Structural reorganization can be a slow process, and this is responsible for the slow changes in the ratio between oligomers and fibers observed on cooling. Conversely, on increasing the gel temperature, the "calving" of oligomers from the fibers requires only the breaking of hydrogen bonds which is rapid. Further structural reorganization of fibers/oligomers may follow, but this is invisible in the EPR spectra. Our results thus clearly demonstrate that any study of supramolecular gels has to allow a sufficiently long time to ensure the equilibration of the gel fibers with the self-assembled oligomers in the solvent pools.

Gel-Sol Transition: Molecular versus Macroscopic

As described above, heating the gel leads to a rapid transition to a sol at $T_{\text {gel }}$ as measured by tube inversion. However, the EPR spectra in Figure $\underline{2}$ show that changes in gel composition actually start at much lower temperatures than the visually observed $T_{\text {gel }}$. To independently confirm this observation, we recorded ${ }^{1} \mathrm{H}$ NMR spectra of unlabeled gels at different temperatures. The immobilization of gelator molecules in the fibers broadens their NMR signals beyond detection; however, free gelator molecules in the solvent pools and possibly small gelator oligomers give reasonably sharp NMR signals. In Figure $\underline{6}$, the integral intensity of NMR signals in the gel, as measured against a mobile internal standard (diphenylmethane), was plotted for several temperatures. The data are complemented by the quantified contribution of the mobile component of the EPR spectra in the same gels incorporating small amounts of spin probe.

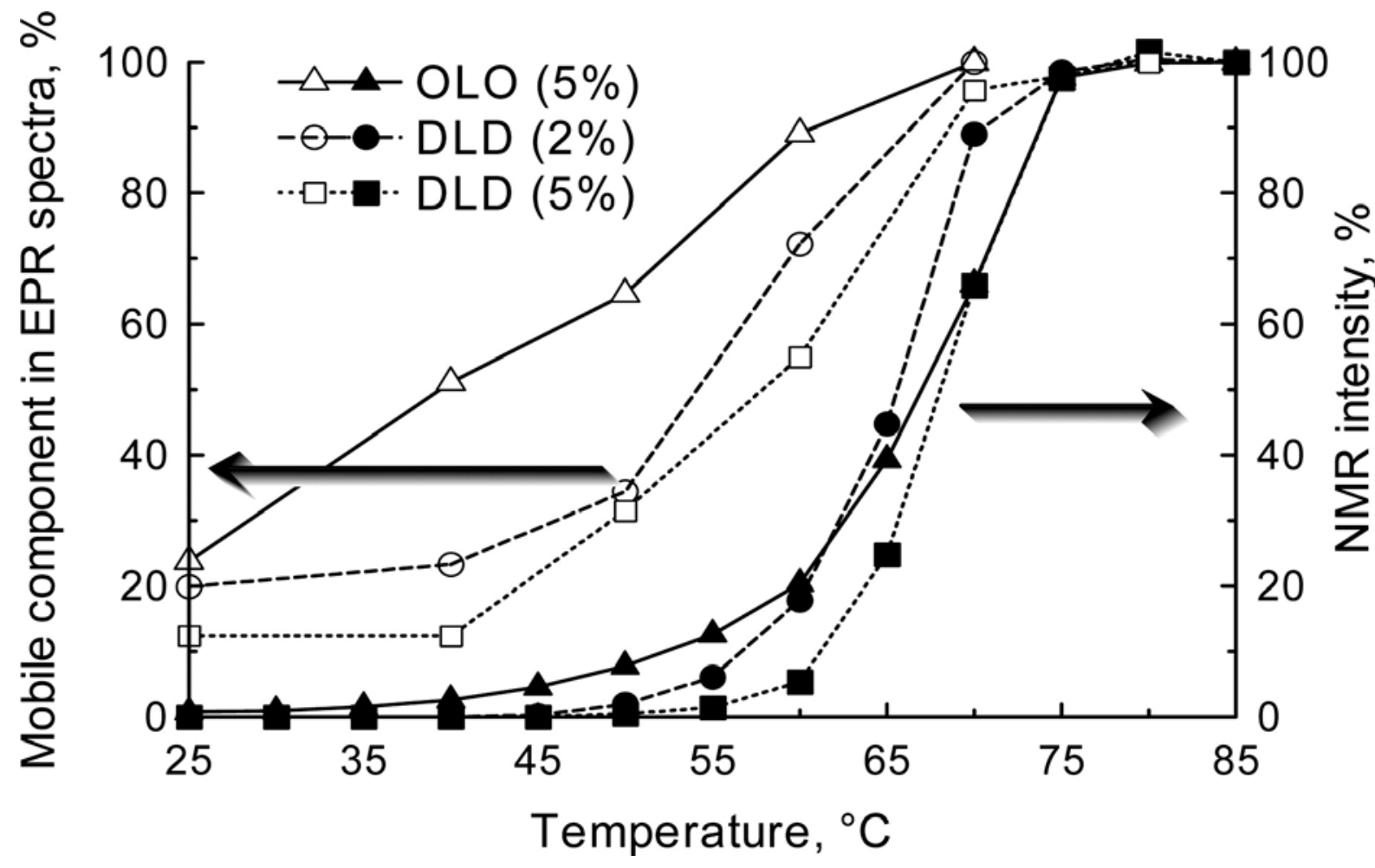


Figure 6. Temperature effect on gel properties as measured by EPR (open symbols) and NMR (filled symbols). Left axis: contribution of the mobile component to the EPR spectra; right axis: relative intensity of the ${ }^{1} \mathrm{H}$ NMR peak.

Figure $\underline{6}$ indicates the NMR and EPR data are in broad agreement. EPR and NMR have different time scales, and so an exact quantitative agreement between these results was not expected. In general, NMR only appears to detect the presence of mobile oligomers/monomers at higher temperatures than EPR (i.e., it appears less sensitive). One should also note that whereas NMR probes the gelator molecules directly, in the EPR experiment this information is relayed only through the spin-labeled gelator present as a dopant - the distribution of this molecule between the fibers and gelator oligomers may not be equal. However, both techniques clearly show that the abrupt macroscopic gel-sol transition corresponds to much more gradual change on the molecular scale. The relative trends in temperature dependence between DLD (2\% and 5\%) and DLD and OLO (both 5\%) are also in agreement in both cases. Both gelator concentration and alkyl chain length have a profound effect on the ratio of oligomers/monomers to immobile fibers. At lower concentration, the proportion of oligomers increases at the expense of the fibers. The shorter alkyl chain also leads to a higher proportion of oligomers at lower temperatures (Figure S3). Gelator Self-Assembly in Dilute Solution

Considering the behavior of gelators below the gelation threshold as probed in the previous experiment, surprisingly little is known about the "solution phase". Given EPR could effectively report on the gradual hierarchical buildup of immobile gel components, we reasoned that it would be a useful technique to shed further light on the true nature of very dilute gelator solutions and may enable us to quantify the early stages of hierarchical assembly of gelator molecules into self-assembled oligomers. We focused on two model systems: self-assembly of just spin-labeled gelator DLT and self-assembly of unlabeled gelator DLD in the presence of the spin-labeled probe TLT.

The DLT label itself (in the absence of unlabeled gelator DLD) does not form a gel in toluene even at high concentrations. Dilute solutions of DLT did not show any evidence of selfassembly at room temperature. However, at lower temperatures, the spectra of DLT solutions showed coexistence of a free mobile label (giving a sharp three-line spectrum) and aggregates (giving a single broad line due to spin-spin interactions between adjacent labels in the aggregate).

Figure $\underline{7}$ (top) shows the EPR spectra of spin-labeled DLT in dilute toluene solutions at 223 $\mathrm{K}$. At this temperature, the changes in the EPR line shape were strong at fairly low concentrations, and the spectra could be easily separated into individual components. This deconvolution is shown in Figure $\underline{7}$ (top) for the $1 \mathrm{mM}$ sample using dashed lines. 

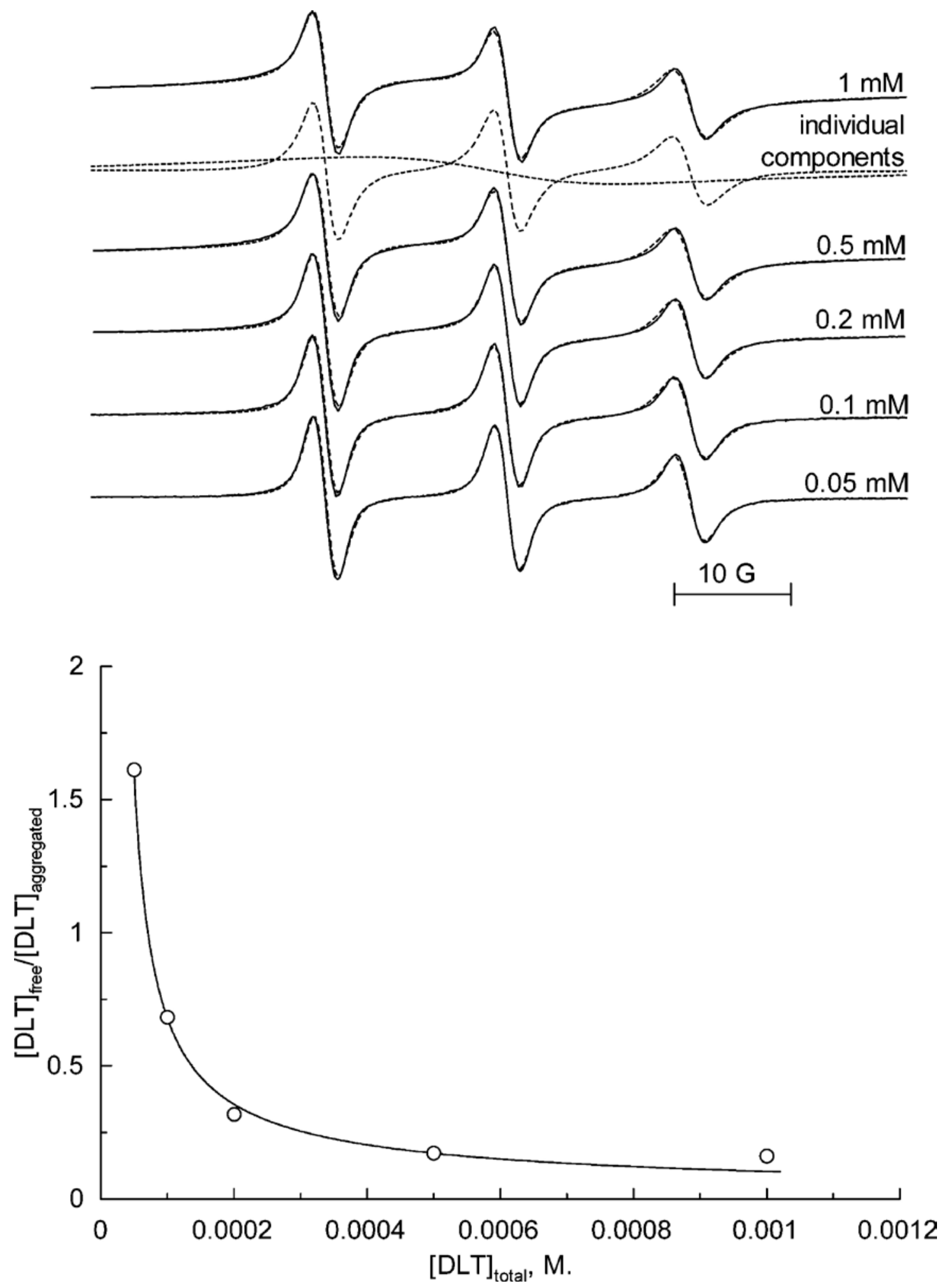

Figure 7. (Top) EPR spectra of DLT at different concentrations recorded at $223 \mathrm{~K}$ in toluene. Experimental spectra and simulations are shown as solid and dashed lines, respectively. For 1 $\mathrm{mM}$ solution, deconvolution of the EPR spectra into two components is shown with dashed lines. (Bottom) Relative proportion of DLT aggregates at different DLT concentrations at 223 K. Fitting parameters for the Goldstein-Stryer model: cooperativity $\sigma=0.977$, cluster size $s=$ 3.88, and equilibrium constant $K=1.54 \times 10^{5} \mathrm{M}^{-1}$. 
The data can be quantitatively analyzed using mathematical models developed for similar processes. For instance, the cooperative Goldstein-Stryer self-assembly model,(37, 38) which was developed for quantitative analysis of supramolecular polymerization. This model assumes that self-assembly is characterized by two equilibrium constants: a smaller constant for the assembly of first few monomers to form a "seed" and a larger constant for the following growth of the seed. The ratio of the two equilibrium constants is termed the cooperativity parameter $\sigma$; thus, for noncooperative assembly $\sigma=1$, and for strongly cooperative assembly $\sigma \ll 1$.

We found that our data fitted the Goldstein-Stryer model with a small cooperativity(39) parameter of 0.977 and an equilibrium constant, $K$, of $1.54 \times 10^{5}$. Figure $\underline{7}$ (bottom) represents the decrease in the relative amount of "free" DLT as the total DLT concentration increases and aggregation becomes more favored. Although the value of the equilibrium constant determined using this fitting process is quite large, it does correspond to selfassembly at a low experimental temperature of $223 \mathrm{~K}$ and at room temperature would be expected to be lower as a consequence of the greater entropic cost of assembly. Nonetheless, these results clearly demonstrate that the formation of supramolecular aggregates may occur quite readily in dilute solutions from this type of molecule even if macroscopic samplespanning gels do not form.

In order to probe the self-assembly of the unlabeled DLD gelator in dilute solutions, we used a diradical label, TLT instead of the DLT label used in the other experiments. TLT is more sensitive to self-assembly as the EPR spectra of such diradicals strongly depend on the conformational space that the diradical can access, as a consequence of intramolecular spinspin interactions.(40) Clearly, upon self-assembly, the conformational space available to TLT will be significantly reduced which should lead to noticeable changes in the EPR spectra. In particular, the EPR spectra of TLT solutions show five-line spectra if the diradicals can adopt ring-like conformations, with the diradicals in close proximity, which have an exchange integral $J$ greater than the isotropic hyperfine constant $a$. Upon self-assembly with DLD molecules, these ring-like conformations should become inaccessible, and the EPR spectrum should consist instead of three lines.

Figure $\underline{8}$ (top) shows a series of EPR spectra of DLD/TLT solutions at different DLD concentrations. The concentration of TLT in each of these samples was $0.1 \mathrm{mM}$. At these dilute conditions, none of these solutions formed a gel at the temperature of the study (294 $\mathrm{K})$. The spectra show two components: a five-line spectrum corresponding to the free TLT molecules and a three-line spectrum corresponding to the TLT bound to other molecules/oligomers. The separation of the two-component spectra into individual components is shown for the $1.33 \mathrm{mM}$ mixture in Figure $\underline{8}$ using dashed lines. It is clear that as concentration increases, the three-line spectrum associated with self-assembly begins to dominate over the five-line spectrum corresponding to free TLT. 

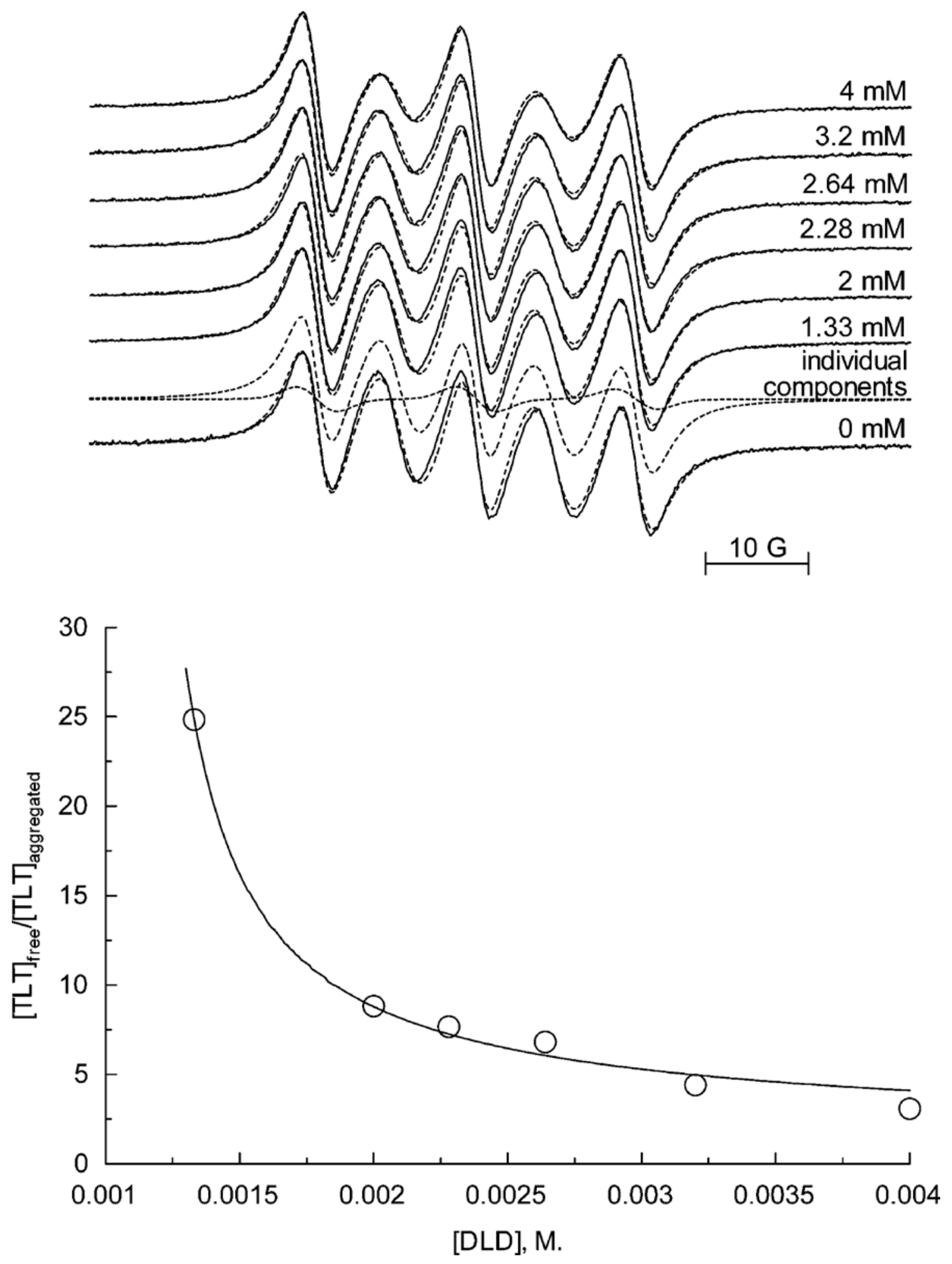

Figure 8. (Top) EPR spectra of DLD/TLT solutions at $294 \mathrm{~K}$. DLD concentrations are shown above each spectrum. Experimental spectra and simulations are shown with solid and dashed lines, respectively. For [DLD] $=1.33 \mathrm{mM}$, the deconvolution of the spectra into free and aggregated components is shown with dashed lines. (Bottom) Relative proportion of aggregated TLT at different DLD concentrations at $294 \mathrm{~K}$. Fitting parameters for the Doerner-Hoskins coprecipitation model and isodesmic self-assembly (the equilibrium constant does not depend on the aggregate size): $K=1887 \mathrm{M}^{-1}$ and $\lambda=0.132$. 
Quantitative analysis of the data is complicated by the fact that it includes two separate selfassembly processes: self-assembly of DLD gelator and the interactions of TLT with the selfassembled aggregates of DLD. We have verified, using EPR, that the third possible process, self-assembly of TLT, does not occur at the concentrations and temperatures used for this experiment (Figure S2). The overall self-assembly is thus akin to coprecipitation, for which quantitative analysis is well established. The interaction of TLT with DLD aggregates was thus modeled assuming Doerner-Hoskins law $(41,42)$ (an established theory of coprecipitation), and self-assembly was assumed to be noncooperative (e.g., an isodesmic approach). Small values of the cooperativity parameter (such as those found for DLT assembly) should not, in any case, affect the quality of fitting, and we felt that the use of a simpler isodesmic model was therefore justified. Interestingly, in a previous study of different gelators, it was shown that in solvents that supported gelation, assembly was cooperative, but that in solvents that failed to support full gelation, the assembly process was isodesmic.(43) This might suggest that at the concentrations well below the gelation threshold being studied here the supramolecular polymerization can indeed be justified as isodesmic, and the fit to experimental data using this model was good. This is consistent with the view that the "seeds" assemble isodesmically and that it is only when extended fiber assembly occurs that any cooperativity is expressed. The obtained value of equilibrium constant for self-assembly of DLD at $294 \mathrm{~K}\left(1187 \mathrm{M}^{-1}\right)$ is quite reasonable and clearly shows that self-assembly occurs not only in the fully formed supramolecular gels themselves but also in highly dilute solutions of gelator molecules well below the gelation threshold. At higher DLD concentrations, the self-assembled aggregates presumably act as points of nucleation for the formation of gel fibers.

Quantifying Solvation of the Gel Fibers Clearly the balance between gelator self-assembly (favored at higher concentrations/lower temperatures) and gelator solvation (favored at lower concentrations and higher temperatures) plays a vital role in ensuring effective gelation. There has been considerable interest in the solvation of gels, and it has often been noted that gelators require intermediate solubility.(44, 45) Many researchers have used solvent parameters to try and rationalize this kind of bulk gelation behavior.(46-51) However, determining the role of solvent in explicitly/directly supporting gelation is a challenging task which has only rarely been accomplished. CD spectroscopy was used to demonstrate that solvent could assist nucleation of gel fibers, with the odd/even nature of the solvent alkane chain controlling the assembly process through direct interactions. $(52,53)$ It has also been shown that the steric demands of the solvent can direct assembly,(54) as can the chirality of the solvent.(55) These effects can only be achieved through direct interaction between solvent molecules and self-assembled nanostructures. In quantitative terms, however, determining the degree of explicit fiber solvation on the nanoscale is an even more challenging task. Recently, NMR has been used to try to achieve this. For example, the dispersion of spin-lattice relaxation times of solvents in the gel phase, observed by NMR relaxometry at low frequencies, as well as relaxation/diffusion experiments have been used as an indicator of the solvent-gelator interactions.(56-58) These studies have shown that an important fraction of the solvent is located within, or explicitly solvated to, the gel fibers. We reasoned that we may be able to use EPR in order to quantify the degree of explicit solvent incorporation/immobilization into/onto our gel fibers.

EPR analysis described above showed that the gelator molecules in the solid-like fibers possess some residual librational motion not observed in the bulk solid gelator (see above, Figure 3 ). This mobility may be due to the solvation of the gel fibers (e.g., incorporation of solvent in the fibers). EPR is sensitive to spin-spin interactions between spin-labels, and the line shape of continuous wave (CW) EPR spectra depends on the distances between the spin- 
labels up to ca. $2 \mathrm{~nm}$. At temperatures significantly lower than the gel transition temperature, nearly all gelator molecules are incorporated into fibers, and at a high spin-label concentration, the labeled gelator molecules in the fibers will be reasonably close to each other; EPR spectra will thus report on the distances between the labels in the fibers, which should in turn reflect the degree of fiber solvation.

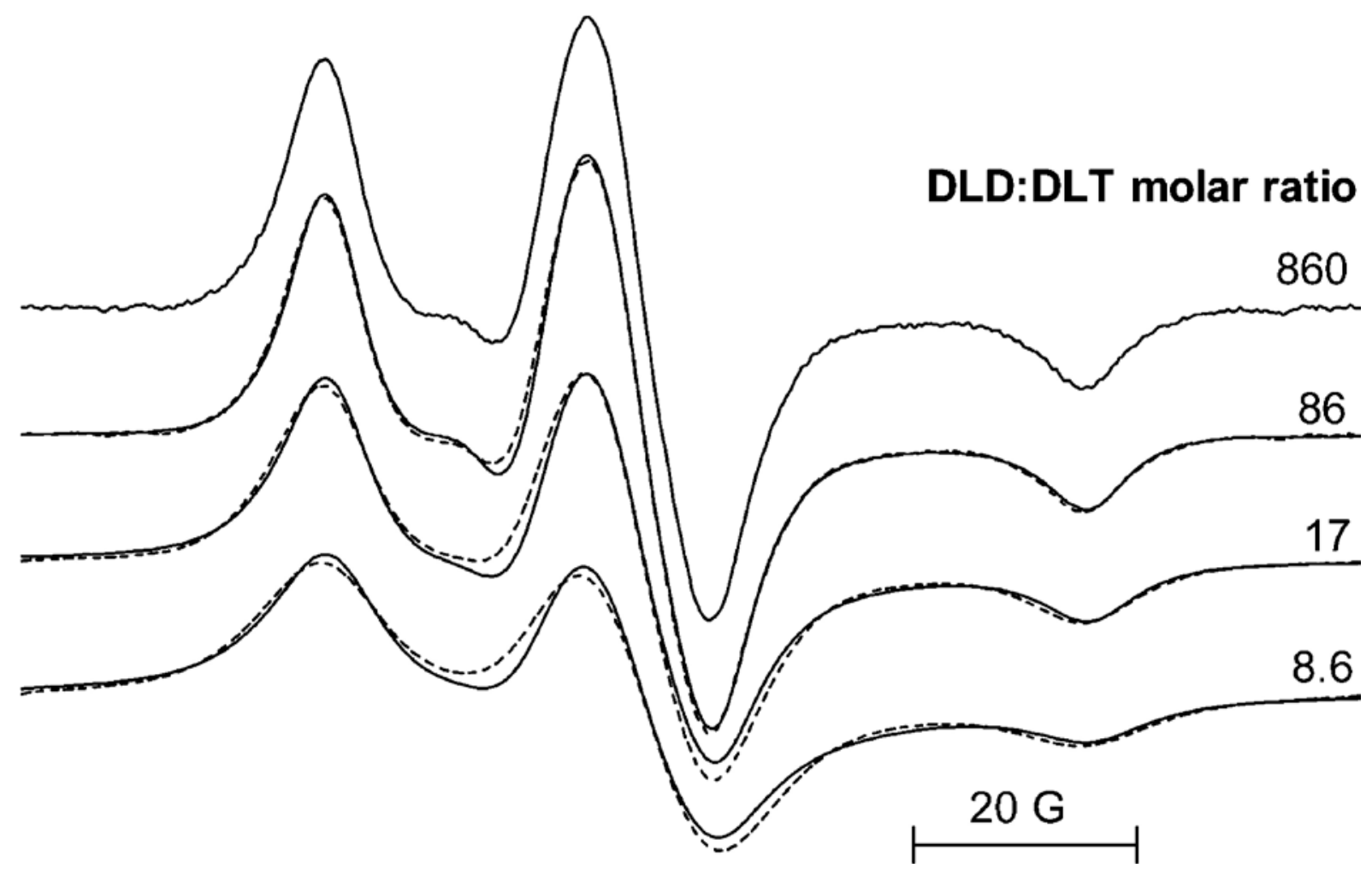

Figure 9. EPR spectra of a 5\% DLD/DLT gel at $120 \mathrm{~K}$. The numbers above the curves are DLD/DLT ratios. The dotted lines are simulations, and the solid lines are experimental.

In order to estimate the effective concentration of the spin-labeled gelator molecules within the gel fibers, we recorded EPR spectra of a 5\% DLD gel with different DLT/DLD ratios at $120 \mathrm{~K}$ (Figure 9). Under these low temperature conditions, all of the DLT is incorporated into the "solid-like" gel fibers, and there is no mobile component. The simulation of CW-EPR spectra of a system containing two spin-labels with a distribution of distances between them can be easily achieved using a point-dipole approximation.(59) This method has been used for the measurement of intermolecular distances in biological macromolecules.(60) Here, we developed a similar approach which assumed a random distribution of spin-labels in 3D space. As the size of gel fibers is much greater than molecular size of the gelator molecules, we feel this assumption is justified. The only variable parameter in our approach was the average "effective concentration" of DLT molecules in the gel fibers.

The validity of this method was tested on a model bulk system with a random distribution of spin-labels, i.e., frozen TEMPO solutions in decalin at different concentrations. Decalin was used instead of toluene as it gives a much better glass upon freezing and prevents formation of crystallites. In gels, formation of a good glass is less important as the spin-labels are immobilized in the gel fibers rather than dissolved in bulk solvent. The analysis of EPR spectra of TEMPO in both frozen decalin and toluene gave a good match between the experimental and predicted concentrations in both cases. However, the quality of spectra 
fitting was much better for decalin. The good quality of simulations and close match of calculated and experimental concentrations validated our approach (Figure S6).

We then applied this simulation approach to the spin-labeled gels (Figure $\underline{9}$ ). The simulation gave a reasonable fit (given the limitations of our simple model) to the experimental gelphase data, and as such, the effective concentration of spin-labels in the gel fibers obtained from the simulations of EPR data can be compared to the expected theoretical concentration. To calculate the expected concentration of spin-labels in the gel fibers, we assumed that the fibers are homogeneous solutions of DLT in DLD (ignoring the incorporation of any solvent in the fibers, Figure 10). This calculation requires the knowledge of the density of DLD in the gel fibers, which was experimentally determined by measuring the volume of the gel, the volume of the solvent in the gel, and the mass of gelator used. The density of the gel fibers (excluding solvent) was $1.007 \pm 0.030 \mathrm{~g} \mathrm{~cm}^{-3}$ which, interestingly, is identical to the density of the neat solid gelator. The calculated expected effective concentrations of DLT in the gel fibers based on a random distribution of DLT units (Figure 10), are shown in Table $\underline{1}$ along with the actual concentrations obtained from the EPR simulations of experimental EPR data.
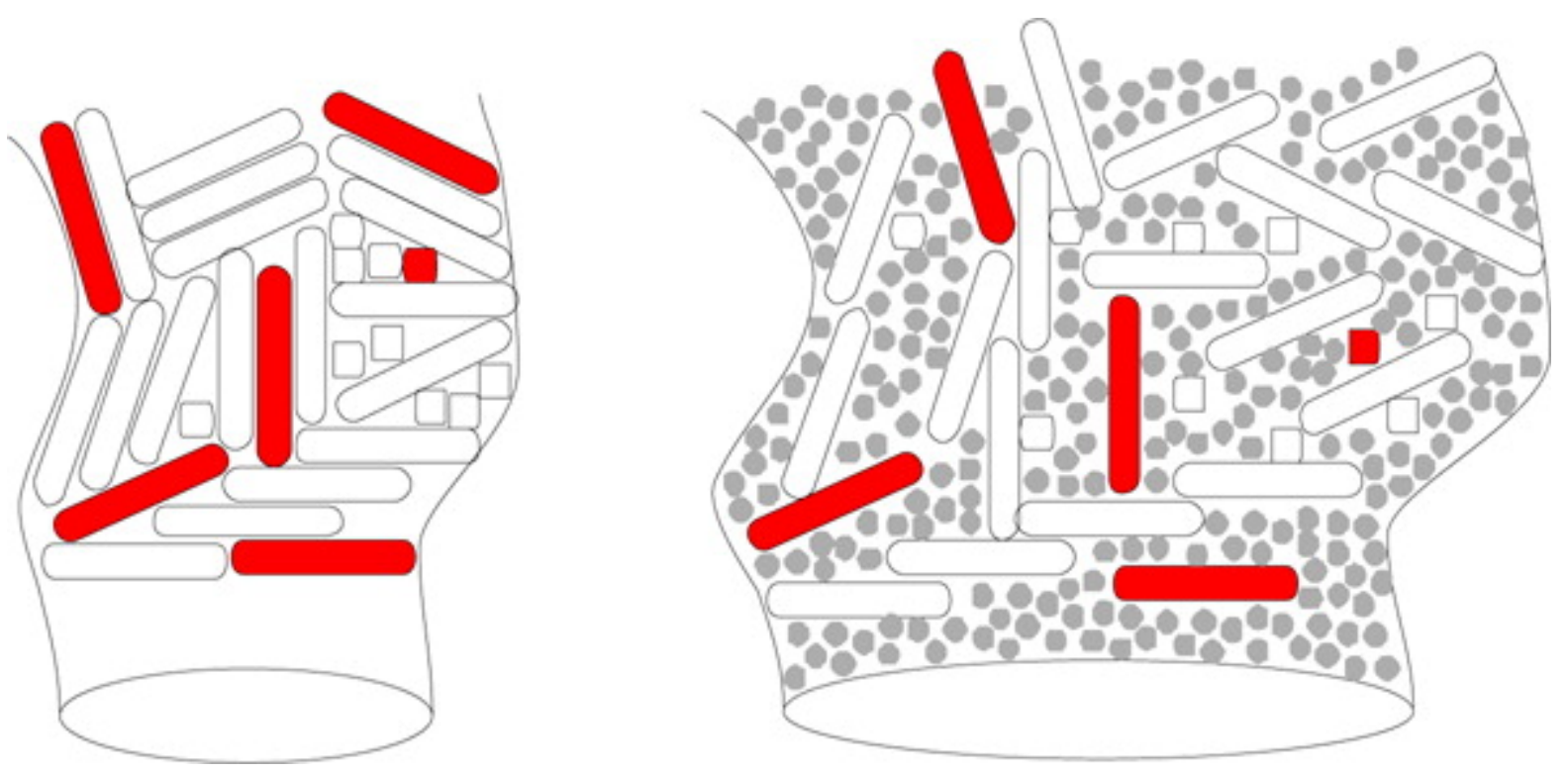

Figure 10. Cartoon showing how the distances between labeled gelator molecules differ for the desolvated (left) and solvated (right) gel fibers. The unlabeled and labeled gelator molecules are shown as empty and filled rectangles, respectively. The solvent molecules are represented as gray spheres.

Table 1. Simulated and Expected Concentrations of DLT in the Gel

simulated from experimental data [DLT], M expected from simple theoretical model [DLT], $\mathbf{a}$
0.0047
0.0201
0.043
0.101
0.0887
0.201

a

Expected [DLT] was calculated assuming the gel fibers are a solution of DLT in DLD and excluding any toluene solvent. 
The concentrations simulated from the experimental EPR data are lower than expected on the basis of the simple theoretical model in every entry in Table 1 . The ratio of concentrations is ca. 2.2 for the last two entries and ca. 4.3 for the top entry. We believe that the discrepancy observed at the lowest concentration of DLT is due to the larger errors associated with measuring the longer spin-spin distances by EPR. In any case, it is clear that the effective concentration of DLT is much smaller than expected, and this must indicate that the volume of the gel fibers is significantly greater than would be expected based on neat gelator alone. This implies that the gel fibers are solvated and swollen by solvent, lowering the effective concentration of DLT and hence increasing the spin-spin distance as observed using EPR. Inspection of the SEM images of the DLD gel(29) (Figure S5) shows a network of intertwined narrow fibrils which presumably are swollen by solvent in wet gels.

Based on the data presented in Table 1 , the gel fibers (at $120 \mathrm{~K}$ ) can be considered to actually be composed of a ca. $43 \mathrm{vol} \%$ solution of gelator in toluene, rather than pure gelator. In total, this would mean that $6.6 \%$ of the available solvent is acting to solvate the gel fibers, and the molar ratio of gelator:solvent in the fiber is ca. 1:7.3. This strong solvation of the gel fibers is also consistent with the librational motion recorded for the spin-labels embedded within them. We believe that this type of EPR distance measurement using a spin-labeled gelator provides one of the most direct methods for estimating the level of explicit solvation of gel fibers.

\section{Conclusions}

In summary, this paper demonstrates how spin-labeling bis-ureas with TEMPO allows them to be used as EPR probes of the gelation of related bis-ureas. Importantly, EPR demonstrates itself as an effective technique for deconvoluting mobile and immobile components within gels and shows itself particularly sensitive (compared to NMR) at detecting larger, yet still mobile, assemblies. In dilute solutions of gelator, EPR is able to probe the association constants for initial steps of hierarchical assembly, which in this system are shown to assemble in a primarily isodesmic manner. Finally, by looking at spin-spin interactions, EPR is able to report on the relative density of spin-labels within gel nanofibers, which gives direct insight into the true structure of these fibers when solvated and hence give an insight into their explicit interaction with solvent molecules. As such, EPR is a powerful technique for gel characterization which can provide information that cannot easily be accessed using other techniques - we believe it will be of broad and general applicabilty in the study of this type of material and has the potential to be widely employed.

Supporting Information

Synthetic and experimental details, additional EPR spectra. This material is available free of charge via the Internet at http://pubs.acs.org.

The authors declare no competing financial interest.

\section{Acknowledgment}


This research was supported by an International Joint Project award from The Royal Society.

- $\quad$ Reference QuickView

-

\section{References}

This article references 60 other publications.

1. 1 .

Molecular Gels: Materials with Self-Assembled Fibrillar Networks; Terech, P., Weiss, R. G., Eds.; Springer: Dordrecht, Netherlands, 2006.

2. $\underline{2}$.

Steed, J. W.Supramolecular Gel Chemistry: Developments over the Last Decade Chem. Commun. 2011, 47, 1379- 1383

[CrossRef], [PubMed], [CAS]

3. $\underline{3}$.

Banerjee, S.; Das, R. K.; Maitra, U.Supramolecular Gels ‘in Action’ J. Mater. Chem. 2009, 19, 6649- 6687

[CrossRef], [모]

4. $\underline{4}$.

Hirst, A. R.; Escuder, B.; Miravet, J. F.; Smith, D. K.High-Tech Applications of SelfAssembling Supramolecular Nanostructured Gel-Phase Materials: From Regenerative Medicine to Electronic Devices Angew. Chem., Int. Ed. 2008, 47, 8002- 8018

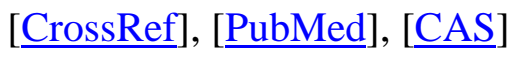

5. $\underline{5}$.

Skilling, K. J.; Citossi, F.; Bradshaw, T. D.; Ashford, M.; Kellam, B.; Marlow, M.Insights Into Low Molecular Mass Organic Gelators: a Focus on Drug Delivery and Tissue Engineering Applications Soft Matter 2014, 10, 237- 256

[CrossRef], [모]

6. $\underline{6}$. 
van Esch, J. H.We Can Design Molecular Gelators, But Do We Understand Them?

Langmuir 2009, 25, 8392- 8394

[ACS Full Text $-\oplus$ ], [PubMed], [CAS]

\section{7. $\underline{7}$}

Raeburn, J.; Cardoso, A. Z.; Adams, D. J.The Importance of the Self-Assembly Process to Control Mechanical Properties of Low Molecular Weight Hydrogels

Chem. Soc. Rev. 2013, 42, 5143- 5156

[CrossRef], [PubMed], [도]

8. $\underline{8}$

Nebot, V. J.; Smith, D. K. Techniques for the Characterisation of Molecular Gels. In Functional Molecular Gels; Escuder, B.; Miravet, J. F., Eds.; RSC Publishing:

Cambridge, UK, 2014; pp 30-66.

9. $\underline{9}$.

Yu, G.; Yan, X.; Han, C.; Huang, F.Characterization of Supramolecular Gels Chem.

Soc. Rev. 2013, 42, 6697-6722

[CrossRef], [PubMed], [CAS]

10. $\underline{10}$.

Hirst, A. R.; Coates, I. A.; Boucheteau, T. R.; Miravet, J. F.; Escuder, B.; Castelletto, V.; Hamley, I. W.; Smith, D. K.Low-Molecular-Weight Gelators: Elucidating the Principles of Gelation Based on Gelator Solubility and a Cooperative Self-Assembly Model J. Am. Chem. Soc. 2008, 130, 9113-9121

[ACS Full Text $-\oplus$ ], [PubMed], [CAS]

11. 11.

Edwards, W.; Smith, D. K.Dynamic Evolving Two-Component Supramolecular Gels-Hierarchical Control over Component Selection in Complex Mixtures J. Am. Chem. Soc. 2013, 135, 5911- 5920

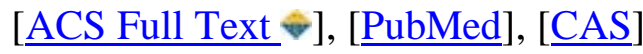

12. 12.

Bouguet-Bonnet, S.; Yemloul, M.; Canet, D.New Application of Proton Nuclear Spin Relaxation Unraveling the Intermolecular Structural Features of Low-MolecularWeight Organogel Fibers J. Am. Chem. Soc. 2012, 134, 10621- 10627

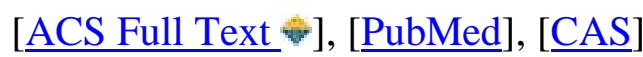




\section{13.}

Smirnov, A. EPR studies of nanomaterials. In Multifrequency Electron Paramagnetic Resonance: Theory and Applications; Misra, S. K., Ed.; Wiley-VCH: Weinheim, Germany, 2011; pp 825- 843.

\section{[CrossRef]}

\section{14.}

Klare, J. Site-Directed Spin Labeling and Electron Paramagnetic Resonance (EPR) Spectroscopy: A Versatile Tool to Study Protein-Protein Interactions. In Protein Interactions; Cai, J.; Wang, R. E., Eds.; InTech: Winchester, 2012; Vol. 21, DOI: $10.5772 / 37209$.

\section{[CrossRef]}

\section{15.}

Chechik, V.; Caragheorgheopol, A. Getting an Inside View of Nanomaterials with Spin Labels and Spin Probes. In Electron Paramagnetic Resonance; Gilbert, B. C.; Davies, M. J.; Murphy, D. M., Eds.; RSC Publishing: Cambridge, UK, 2007; Vol. 20, pp 96- 130.

\section{16.}

Caragheorgheopol, A.; Caldararu, H. EPR Spin-Labelling and Spin-Probe Studies of Self-Assembled Systems. In Electron Paramagnetic Resonance; Gilbert, B. C.; Davies, M. J.; McLauchlan, K. A., Eds.; RSC Publishing: Cambridge, UK, 2000; Vol. 17, pp 205- 245.

\section{[CrossRef]}

\section{17.}

Lucarini, M.; Mezzina, E. EPR Investigations of Organic Non-Covalent Assemblies with Spin Labels and Spin Probes. In Electron Paramagnetic Resonance; Gilbert, B. C.; Murphy, D. M.; Chechik, V., Eds.; RSC Publishing: Cambridge, UK, 2011; Vol. 22, pp 41- 70 .

18. 18.

Nakabayashi, K.; Kawano, M.; Yoshizawa, M.; Ohkoshi, S.-i.; Fujita, M.CavityInduced Spin-Spin Interaction between Organic Radicals within a Self-Assembled Coordination Cage J. Am. Chem. Soc. 2004, 126, 16694- 16695

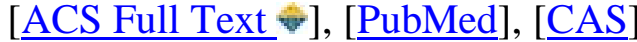

19. 19. 
Hinderberger, D.EPR Spectroscopy in Polymer Science Top. Curr. Chem. 2012, 321, 67- 89

[CrossRef], [PubMed], [CAS]

20. $\underline{20}$.

Ruthstein, S.; Goldfarb, D. An EPR Tool Box for Exploring the Formation and Properties of Ordered Template Mesoporous Materials. In Electron Paramagnetic Resonance; Gilbert, B. C.; Davies, M. J.; Murphy, D. M., Eds.; RSC Publishing: Cambridge, UK, 2008; Vol. 21, pp 184- 215.

\section{[CrossRef]}

21. 21.

Lucarini, M.; Pasquato, L.ESR Spectroscopy as a Tool to Investigate the Properties of Self-Assembled Monolayers Protecting Gold Nanoparticles Nanoscale 2010, 2, 66876

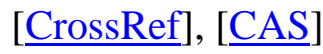

22. 22.

Kveder, M.; Andreis, M.; Makarevic, J.; Jokic, M.; Rakvin, B.EPR Study of Low Molecular Weight Organogels by Means of a Nitroxide Spin Probe Chem. Phys. Lett. 2006, 420, 443- 447

[CrossRef], [Aㅗ]

23. 23.

Andreis, M.; Caric, D.; Vujicic, N. S.; Jokic, M.; Zinic, M.; Kveder, M.Self-Assembly of Gelator Molecules in Liquid Crystals Studied by ESR Chem. Phys. 2012, 403, 8188

\section{[CrossRef], [CAS]}

24. 24.

Puigmarti-Luis, J.; del Pino, A. P.; Laukhin, V.; Feldborg, L. N.; Rovira, C.;

Laukhina, E.; Amabilino, D. B.Solvent Effect on the Morphology and Function of

Novel Gel-Derived Molecular Materials J. Mater. Chem. 2010, 20, 466- 474

[CrossRef], [CAS]

\section{5. $\underline{25}$.}


Mannini, M.; Cicchi, S.; Berti, D.; Caneschi, A.; Brandi, A.; Lascialfari, L.; Sorace, L.Radical-Functionalised Gel: A Building-Block Strategy for Magnetochiral Assembly ChemPlusChem 2013, 78, 149- 156

\section{[CrossRef], [소 $]$}

26. 26.

Wu, Y.; Hirai, Y.; Tsunobuchi, Y.; Tokoro, H.; Eimura, H.; Yoshio, M.; Ohkoshi, S.; Kato, T.Supramolecular Approach to the Formation of Magneto-Active Physical Gels Chem. Sci. 2012, 3, 3007- 3010

[CrossRef], [CAS]

27. 27.

Yamanaka, M.Urea Derivatives as Low-Molecular-Weight Gelators J. Inclusion Phenom. Macrocyclic Chem. 2013, 77, 33- 48

[CrossRef], [로 $]$

28. 28.

Steed, J. W.Anion-Tuned Supramolecular Gels: a Natural Evolution from Urea Supramolecular Chemistry Chem. Soc. Rev. 2010, 39, 3686- 3699

[CrossRef], [PubMed], [슬

29. 29.

Hardy, J. G.; Hirst, A. R.; Ashworth, I. A.; Brennan, C.; Smith, D. K.Exploring Molecular Recognition Pathways within a Family of Gelators with Different Hydrogen Bonding Motifs Tetrahedron 2007, 63, 7397- 7406

\section{[CrossRef], [Aㅗ]}

30. $\underline{30 .}$

Coates, I. A.; Smith, D. K.Controlled Self-Assembly - Synthetic Tunability and Covalent Capture of Nanoscale Gel Morphologies Chem.—Eur. J. 2009, 15, 63406344

\section{[CrossRef], [PubMed], [슬}

\section{1. $\underline{31}$.}

Saracino, G. A. A.; Tedeschi, A.; D’Errico, G.; Improta, R.; Franco, L.; Ruzzi, M.; Corvaia, C.; Barone, V.Solvent Polarity and pH Effects on the Magnetic Properties of Ionizable Nitroxide Radicals: A Combined Computational and Experimental Study of 
2,2,5,5-Tetramethyl-3-carboxypyrrolidine and 2,2,6,6-Tetramethyl-4-

carboxypiperidine Nitroxides J. Phys. Chem. A 2002, 106, 10700- 10706

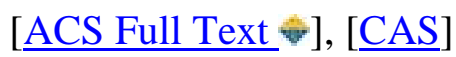

32. 32.

Budil, D. E.; Lee, S.; Saxena, S.; Freed, J. H.Nonlinear-Least-Squares Analysis of Slow-Motion EPR Spectra in One and Two Dimensions Using a Modified Levenberg-Marquardt Algorithm J. Magn. Reson., Ser. A 1996, 120, 155- 189

[CrossRef], [Aㅗ

33. $\underline{33}$.

Di Lorenzo, M. L.; Cocca, M.; Gentile, G.; Avella, M.; Gutierrez, D.; Della Pirriera, M.; Kennedy, M.; Ahmed, H.; Doran, J.Thermoreversible Luminescent Organogels Doped with Eu(TTA) )sphen Complex J. Colloid Interface Sci. 2013, 398, 95- 102

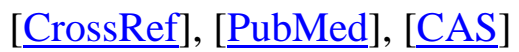

34. $\underline{34}$.

Roy, B.; Saha, A.; Esterrani, A.; Nandi, A. K.Time Sensitive, Temperature and pH Responsive Photoluminescence Behaviour of a Melamine Containing Bicomponent Hydrogel Soft Matter 2010, 6, 3337- 3345

[CrossRef], [AS]

35. $\underline{35}$.

Huang, X.; Terech, P.; Raghavan, S. R.; Weiss, R. G.Kinetics of $5 \alpha$-Cholestan-3 $\beta$-yl $\mathrm{N}$-(2-Naphthyl)carbamate/n-Alkane Organogel Formation and Its Influence on the Fibrillar Networks J. Am. Chem. Soc. 2005, 127, 4336- 4344

[ACS Full Text $\oplus$ ], [PubMed], [CAS]

36. 36.

Huang, X.; Raghavan, S. R.; Terech, P.; Weiss, R. G.Distinct Kinetic Pathways Generate Organogel Networks with Contrasting Fractality and Thixotropic Properties J. Am. Chem. Soc. 2006, 128, 15341- 15352

[ACS Full Text $-\oplus$ ], [PubMed], [CAS]

\section{37.}

Goldstein, R. F.; Stryer, L.Cooperative polymerization reactions. Analytical approximations, numerical examples, and experimental strategy Biophys. J. 1986, 50, 583- 599 
[CrossRef], [PubMed], [Aㅗ]

38. 38.

De Greef, T. F. A.; Smulders, M. M. J.; Wolffs, M.; Schenning, A. P. H. J.; Sijbesma, R. P.; Meijer, E. W.Supramolecular Polymerization Chem. Rev. 2009, 109, 56875754

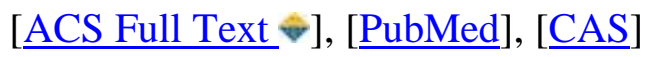

39. 39.

Hunter, C. A.; Anderson, H. L.What is Cooperativity? Angew. Chem., Int. Ed. 2008, 48, 7488- 7499

\section{[CrossRef]}

40. $\underline{40}$.

Grampp, G.; Landgraf, S.; Grigor’ev, I. A.; Shapiro, A. B.; Kokorin, A.

I.Intramolecular Spin Exchange in Flexible Short-Chain Biradicals in Solutions with

Various Viscosity Appl. Magn. Reson. 2000, 26, 245- 252

[CrossRef]

41. 41.

Townshend, A.; Jackwerth, E.Precipitation of Major Constituents for Trace

Preconcentration: Potential and Problems Pure Appl. Chem. 1989, 61, 1643- 1656

[CrossRef]

42. $\underline{42 .}$

Munakata, M.; Toyomasu, S.Quantitative Treatment of the Distribution Coefficient for Coprecipitation of Metal Oxalates Anal. Chem. 1972, 44, 2057- 2060

\section{[ACS Full Text $-\oplus$ ], [CAS]}

43. 43.

Aparicio, F.; Garcia, F.; Sanchez, L.Supramolecular Polymerization of $\mathrm{C}_{3}$-Symmetric Organogelators: Cooperativity, Solvent, and Gelation Relationship Chem.-Eur. J. 2013, 19, 3239- 3248

[CrossRef], [PubMed], [Aㅗ]

44. 44. 
Smith, D. K.Molecular Gels - Underpinning Nanoscale Materials with Organic

Chemistry Tetrahedron 2007, 63, 7283- 7284

[CrossRef], [모]

45. 45.

Niu, L.; Song, J.; Li, J.; Tao, N.; Lu, M.; Fan, K.Solvent Effects on the Gelation Performance of Melamine and 2-Ethylhexylphosphoric Acid Mono-2-ethylhexyl Ester in Water-Organic Mixtures Soft Matter 2013, 9, 7780- 7786

[CrossRef], [Aㅗ]

46. $\underline{46}$.

Bielejewski, M.; Lapinski, A.; Luboradzki, R.; Tritt-Goc, J.Solvent Effect on 1,2-O(1-Ethylpropylidene)- $\alpha$-d-glucofuranose Organogel Properties Langmuir 2009, 25, 8274- 8279

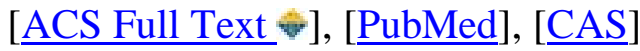

47. 47.

Rogers, M. A.; Marangoni, A. G.Solvent-Modulated Nucleation and Crystallization Kinetics of 12-Hydroxystearic Acid: A Nonisothermal Approach Langmuir 2009, 25, 8556- 8566

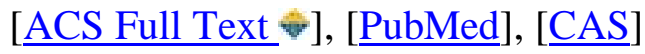

48. $\underline{48}$.

Raynal, M.; Bouteiller, L.Organogel Formation Rationalized by Hansen Solubility Parameters Chem. Commun. 2011, 8271- 8273

[CrossRef], [PubMed], [A]

49. 49.

Muro-Small, M. L.; Chen, J.; McNeil, A. J.Dissolution Parameters Reveal Role of Structure and Solvent in Molecular Gelation Langmuir 2011, 27, 13248- 13253

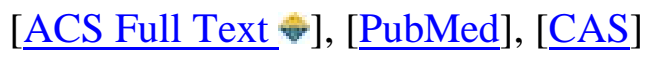

50. $\underline{50 .}$

Wu, S.; Gao, J.; Emge, T. J.; Rogers, M. A.Influence of Solvent on the

Supramolecular Architectures in Molecular Gels Soft Matter 2013, 9, 5942- 5950

[CrossRef], [Aㅗ] 


\section{51.}

Fan, K.; Niu, L.; Li, J.; Feng, R.; Qu, R.; Liu, T.; Song, J.Application of Solubility Theory in Bi-component Hydrogels of Melamine with Di(2-ethylhexyl)phosphoric Acid Soft Matter 2013, 9, 3057- 3062

\section{[CrossRef], [도]}

\section{52.}

Jonkheijm, P.; van der Schoot, P.; Schenning, A. P. H. J.; Meijer, E. W.Probing the Solvent-Assisted Nucleation Pathway in Chemical Self-Assembly Science 2006, 313, 80- 83

\section{[CrossRef], [PubMed], [CAS]}

\section{3. $\underline{53 .}$}

Cantekin, S.; Nakano, Y.; Everts, J. C.; van der Schoot, P.; Meijer, E. W.; Palmans, A. R. A.A Stereoselectively Deuterated Supramolecular Motif to Probe the Role of Solvent During Self-Assembly Processes Chem. Commun. 2012, 48, 3803- 3805

[CrossRef], [PubMed], [ㄷS]

\section{54.}

Pinault, T.; Isare, B.; Boutellier, L.Solvents with Similar Bulk Properties Induce Distinct Supramolecular Architectures ChemPhysChem 2006, 7, 816- 819

[CrossRef], [PubMed], [CAS]

\section{5. $\underline{55}$.}

Mukai, M.; Minamikawa, H.; Aoyagi, M.; Asakawa, M.; Shimizu, T.; Kogiso, M.Solvent-Chirality Selective Organogelation by Chiral Aspartame Lipids Soft Matter 2012, 8, 11979- 11981

[CrossRef], [Aㅗ]

56. $\underline{56}$.

Yemloul, M.; Steiner, E.; Robert, A.; Bouguet-Bonnet, S.; Allix, F.; Jamart-Gregoire, B.; Canet, D.Solvent Dynamical Behavior in an Organogel Phase As Studied by NMR Relaxation and Diffusion Experiments J. Phys. Chem. B 2011, 115, 2511- 2517

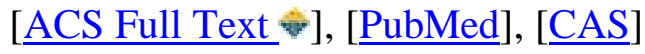

$57 . \underline{57}$. 
Tritt-Goc, J.; Bielejewski, M.; Luboradzki, R.Interaction of Chlorobenzene with Gelator in Methyl-4,6-O-(p-nitrobenzylidene)- $\alpha$-d-glucopyranoside Gel Probed by Proton Fast Field Cycling NMR Relaxometry Tetrahedron 2011, 67, 8170- 8176

[CrossRef], [도]

58. 58.

Bielejewski, M.; Kowalczuk, J.; Kaszynska, J.; Lapinski, A.; Luboradzki, R.; Demchuk, O.; Tritt-Goc, J.Novel Supramolecular Organogels Based on a Hydrazide Derivative: Non-Polar Solvent-Assisted Self-Assembly, Selective Gelation Properties, Nanostructure, Solvent Dynamics Soft Matter 2013, 9, 7501- 7514

[CrossRef], [도]

59. 59.

Riplinger, C.; Kao, J. P. Y.; Rosen, G. M.; Kathirvelu, V.; Eaton, G. R.; Eaton, S. S.; Kutateladze, A.; Neese, F.Interaction of Radical Pairs Through-Bond and ThroughSpace: Scope and Limitations of the Point-Dipole Approximation in Electron Paramagnetic Resonance Spectroscopy J. Am. Chem. Soc. 2009, 131, 10092- 10106

[ACS Full Text $\odot$ ], [PubMed], [CAS]

60. 60.

Steinhoff, H. J.; Radzwill, N.; Thevis, W.; Lenz, V.; Brandenburg, D.; Antson, A.; Dodson, G.; Wollmer, A.Determination of Interspin Distances Between Spin Labels Attached to Insulin: Comparison of Electron Paramagnetic Resonance Data with the X-Ray Structure Biophys. J. 1997, 73, 3287- 3298

[CrossRef], [PubMed], [CAS] 